\title{
6.6 kW On-Vehicle Charger with a Hybrid Si IGBTs and SiC SBDs Based Booster Power Module
}

\author{
Timothy Junghee Han $^{\dagger}$, Jared Preston ${ }^{*}$, and David Ouwerkerk \\ ${ }^{\dagger *}$ Global Power Electronics, Inc., California, USA
}

\begin{abstract}
In this paper, a hybrid booster power module with Si IGBT and Silicon Carbide (SiC) Schottky Barrier Diode (SBDs) is presented. The switching characteristics of the hybrid booster module are compared with commercial Silicon IGBT/Si PIN diode based modules. We applied the booster power module into a non-isolated on board vehicle charger with a simple buck-booster topology. The performances of the on-vehicle charger are analyzed and measured with different power modules. The test data is measured in the same system, at the same points of operation, using the conventional Si and hybrid Si/SiC power modules. The measured power conversion efficiency of the proposed on-vehicle charger is $96.4 \%$ with the SiC SBD based hybrid booster module. The conversion efficiency gain of $1.4 \%$ is realizable by replacing the Si-based booster module with the Si IGBT/SiC SBD hybrid boost module in the $6.6 \mathrm{~kW}$ on-vehicle chargers.
\end{abstract}

Keywords: Silicon Carbide (SiC), Hybrid Booster Power Module, On-Vehicle Charger.

\section{INTRODUCTION}

Hybrid electrical vehicles (HEVs), plug-in hybrid electrical vehicles (PHEVs), and battery electrical vehicles (BEVs) are now revealed as one of the promising environment friendly vehicle technologies. These $\mathrm{xEVs}$ will reduce the usage of petroleum, air pollution, and the emission of carbon dioxide. Since these XEVs are critically depend on the availability of batteries and battery charging infrastructure, the progress of low cost reliable batteries is the key element to increase deployment of the xEVs near future [1], [2]. Battery chargers are another key component required for the emergence and acceptance of PHEVs/BEVs. For PHEVs/BEVs applications, the automotive industry accepted using an on-vehicle charger. An on-vehicle 3.3/6.6 kW charger can charge a $16 \mathrm{kWh}$ depleted battery pack in PHEV's to 80\% charge in less than eight/four hours from a 120/220 VAC supply [3].

High power conversion efficiency and high operating temperature capability is essential for on-vehicle battery charger to minimize recharging time and to withstand the brutal high temperature environments [4]. Silicon Carbide $(\mathrm{SiC})$ is a wide band-gap semiconductor technology that

Manuscript received Jan. 30, 2013; revised May 21, 2013 Recommended for publication by Associate Editor Jin Hur.

${ }^{\dagger}$ Corresponding Author: jhhan@gpe-energy.com

Tel: +1-949-216-8792, Fax: +1-949-613-7600, Global Power Electronics

* Global Power Electronics, Inc., California, USA offers high temperature capability and fast switching speeds in vehicle charger applications [5].

Therefore, SiC semiconductor devices, especially Schottky Barrier Diodes (SBDs) for booster with power factor correction function, have the potential to realize efficiency gains in on-vehicle chargers and other applications [6]-[9]. SiC SBDs have negligible reverse recovery which virtually eliminates large portion of switching loss. While conduction losses and switching losses of the Si IGBTs could be optimized in high voltage circuits which will show substantial improvement in terms of lower power conversion losses. SiC has replaced most junction and metal barrier diodes in power factor correction converters and are both reliable and low cost. By combining the advantages of generation 3 IGBTs and the zero reverse recovery of $\mathrm{SiC}$ rectifiers, we can make a high speed, low loss, reliable, low cost power module that will improve the overall efficiency of the power electronics and also shrink the size of high power converters by increasing the switching frequency.

The designed hybrid Si IGBT-SiC SBDs power module utilized the latest high speed, high efficient, silicon IGBTs and SiC freewheeling SBD diodes. The module package is form, fit, and functionally equivalent to an automotive or commercial module package currently being sourced in high volume from a leading power module manufacturer. The strategy of using a widely accepted commercial module package with improved semiconductors will shorten 
TABLE I

SPeCifiCATION OF Si-SiC Hybrid Boost Module

\begin{tabular}{|l|c|c|c|}
\hline Parameters & Symbol & Specifications & Units \\
\hline $\begin{array}{l}\text { Collector - Emitter } \\
\text { Breakdown Voltage }\end{array}$ & $\mathrm{V}_{\mathrm{CES}}$ & 1200 & $\mathrm{~V}$ \\
\hline $\begin{array}{l}\text { Max Continuous } \\
\text { Collector Current }\end{array}$ & \begin{tabular}{c}
$\mathrm{I}_{\mathrm{C} @ \text { one }} \mathrm{IGBT}$ \\
\hline $\begin{array}{l}\text { Max Gate-Emitter } \\
\text { Voltage }\end{array}$
\end{tabular} $\mathrm{V}_{\mathrm{GES}}$ & 40 & $\mathrm{~A}$ \\
\hline $\begin{array}{l}\text { SiC Diode Forward } \\
\text { Voltage @ 30A }\end{array}$ & $\mathrm{V}_{\mathrm{F}}$ & 1.7 & $\mathrm{~V}$ \\
\hline $\begin{array}{l}\text { Maximum Reverse } \\
\text { Leakage Current }\end{array}$ & $\mathrm{I}_{\mathrm{RM}}$ & 160 & $\mu \mathrm{A}$ \\
\hline $\begin{array}{l}\text { Operating Junction } \\
\text { Temperature }\end{array}$ & $\mathrm{T}_{\mathrm{j}}$ & $-55 \sim+150$ & ${ }^{0} \mathrm{C}$ \\
\hline
\end{tabular}

development time, enhance acceptance, and increase chances for commercialization.

This paper presents design and characterization of the $\mathrm{Si}$ IGBTs / SiC SBDs based a hybrid booster module in section II. Section III describes the non-isolated $6.6 \mathrm{~kW}$ on-vehicle charger, followed by experimental results in section IV, and the conclusions are presented in section V.

\section{Hybrid BOOSTER POWER MOdUle}

GPE has developed a Hybrid Si IGBTs / SiC SBDs boost power module with a SOT-227 package as shown in Table 1. The boost module can support up to rated voltage of $1200 \mathrm{~V}$ and at diode current of $60 \mathrm{~A}$. The module is integrated with the field-stop trenched Si IGBTs (40 A per IGBT), the fast recovery Si PIN freewheeling diodes (15 A per PIN diode), and the SiC boost SBDs (30 A per SBD).

As shown in Fig. 1, The Si IGBTs, Si FRED, and the SiC dies are attached on the $9 \% \mathrm{ZrO}_{2}$ doped $\mathrm{Al}_{2} \mathrm{O}_{3}$ direct bond copper (DBC) substrate with minimum inductance loop between IGBTs and the boost SiC SBDs. The isolation voltage of the ceramic substrate provides $2500 \mathrm{~V}$ isolation between the power devices and the baseplate. For the automotive applications, the $0.32 \mathrm{~mm}$ thickness of the substrate is selected with the $0.2 \mathrm{~mm}$ copper on the top and $0.127 \mathrm{~mm}$ copper on the bottom side of the DBC substrate. The solder joints both die \& substrate and the substrate \& baseplate are formed at a reflow solder systems with 96.5Sn3.5Ag eutectic solder. The top-side die contact is done with 12 mil Aluminum wires except for the gate contact 8 mil Aluminum wire. The selected mold compound is Hysol MG15F-140 from Henkel.

The performances of the hybrid module are compared with the commercially available Si-based power modules with the same SOT-227 package as shown in Table II.

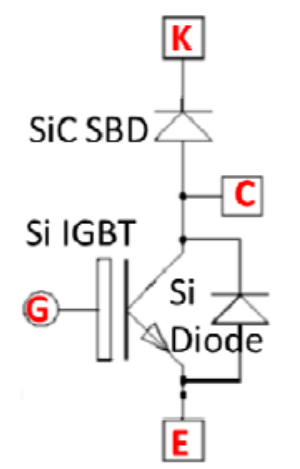

(a) Chematic drawing.

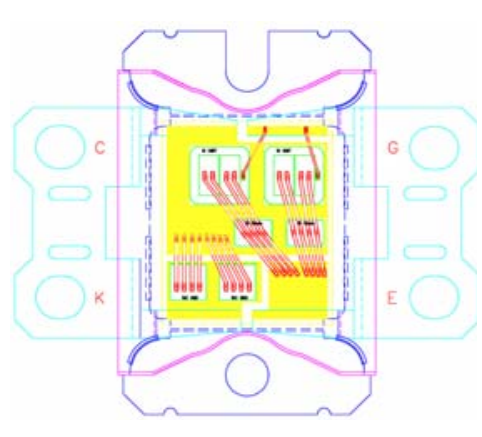

(b) Boost module layout.

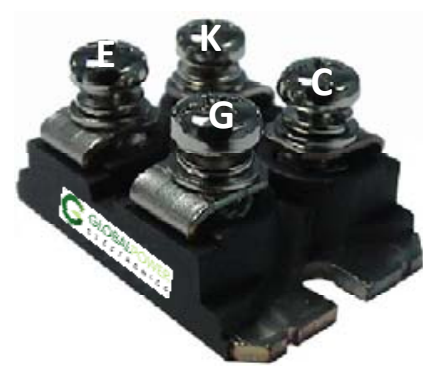

(c) Picture of the hybrid boost module.

Fig. 1. Hybrid boost module with SOT-227 package.

TABLE II

List OF Boost MOdULES Under Evaluation

\begin{tabular}{|l|l|}
\hline Vendors & Part Numbers \\
\hline Global Power Electronics, Inc. & GHIS030A120S-A1 \\
\hline Microsemi Corporation & APT75GT120JU2 \\
\hline Vishay Intertechnology, Inc. & GB50LA120UX \\
\hline
\end{tabular}

The switching losses of the boost module were measured using a double pulse tester (DPT) with $200 \mu \mathrm{H}$ inductive load as shown in Fig. 2 [10]. In the experiments, the module is tested at a $600 \mathrm{~V}$ DC bus voltage, $40 \mathrm{~A}$ current, and $150{ }^{\circ} \mathrm{C}$ junction temperature. The self-heating of the devices is not considered and the junction temperature is assumed the same as the case temperature because of the slow thermal time constant compared to the double pulse duration, repetition time $2 \mathrm{~ms}$, turn-on pulse time $2 \sim 5 \mu \mathrm{s}$.

The measured switching losses of the GPE hybrid module with different gate resistors are shown in Fig. 3. The turn-on switching loss (solid lines) is linearly depend on the gate resistor, however, the turn-off switching loss (dotted lines) changes are very small since the long turn-off tail of the IGBT is not effected by the gate resistor values. Fig. 4 shows the rise time $\left(\mathrm{t}_{\mathrm{r}}\right)$ and fall time $\left(\mathrm{t}_{\mathrm{f}}\right)$ of the switching corrector current from $10 \%$ to $90 \%$ changes. Degradation of the falling time at high junction temperature is a typical behavior of the designed field-stop trenched Si IGBT device [11]. 


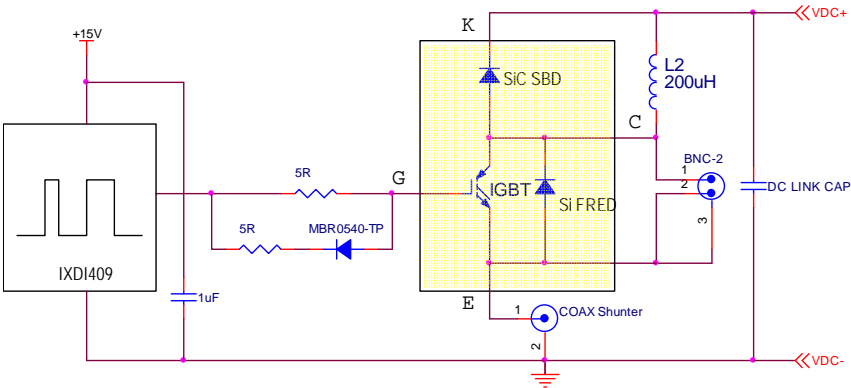

(a) Schematic drawing of DPT circuits.

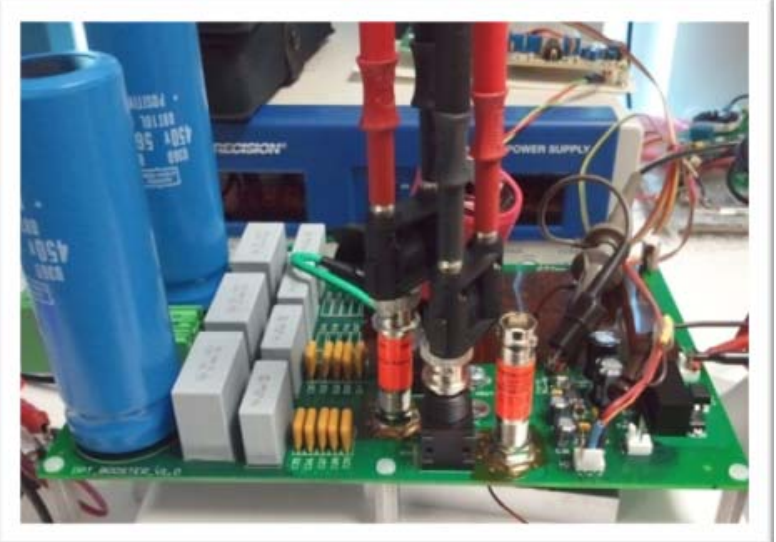

(b) Picture of the DPT board.

Fig. 2. Test configuration of switching characteristics.

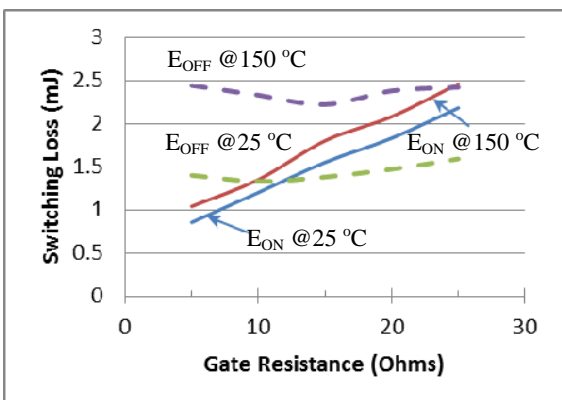

Fig. 3. Switching Loss vs. gate resistor with $\mathrm{V}_{\mathrm{CE}}=600 \mathrm{~V}, \mathrm{I}_{\mathrm{C}}=40$ $\mathrm{A}, \mathrm{T}_{\mathrm{J}}=25 \sim 150{ }^{\circ} \mathrm{C}$, and $\mathrm{V}_{\mathrm{GE}}=15 \mathrm{~V}$.

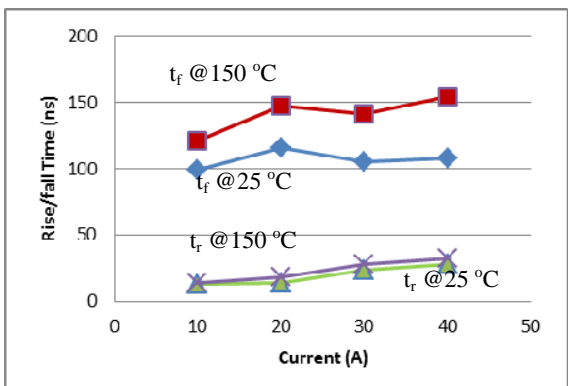

Fig. 4. Rise $\left(\mathrm{t}_{\mathrm{r}}\right)$ and fall time $\left(\mathrm{t}_{\mathrm{f}}\right)$ vs. collector current with $\mathrm{V}_{\mathrm{CE}}=600 \mathrm{~V}, \mathrm{R}_{\mathrm{G}}=5 \mathrm{ohm}$, and $\mathrm{V}_{\mathrm{GE}}=15 \mathrm{~V}$.

The switching characteristics of the hybrid booster module are compared with Si IGBT/Si PIN based booster power modules. As shown in Fig. 5(c), the turn-on overshoot current of the $\mathrm{Si}$ based module is $90 \mathrm{~A}$ at $150{ }^{\circ} \mathrm{C}$ due to the discharging current of reverse recovery charge of the boost diodes. It is verified in [12] that the use of SiC SBD, which has negligible reverse recovery current, helps to reduce the turn-on overshoot current of the IGBT. The IGBT chip accommodated in Vishay's booster module has very good switching waveforms, however, the IGBT is designed with high forward voltage drop [13].

The waveforms of the turn on/off switching losses are shown in Fig. 6. The turn-on loss is dominated by the overshoot current due to the discharging current of reverse recovery charges of the boost diode. On the other hand, the switching tail current of the IGBT as shown in Fig. 5 (d) is a significant impact on the turn-off loss. In the GPE Rev2 module, the field-stop trenched IGBT design is optimized between the forward voltage drop and the turn-off tailing current[9]. By replacing a Si PIN boost diode with the SiC SBD, the peak current at the turn-on transient instant was reduced from $90 \mathrm{~A}$ to $50 \mathrm{~A}$. It is a significant impact on not just the turn-on switching losses, but also on the EMI/EMC performances.

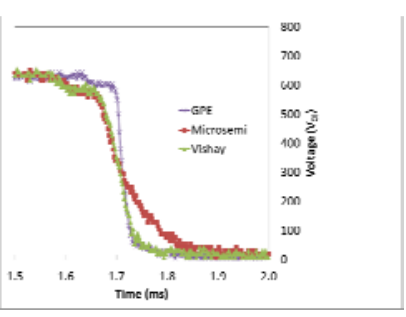

(a) $\mathrm{V}_{\mathrm{CE}}$ at Turn-on.

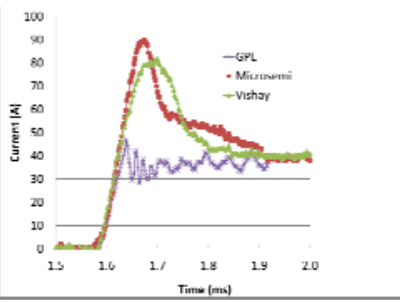

(c) $\mathrm{I}_{\mathrm{C}}$ at Turn-on.

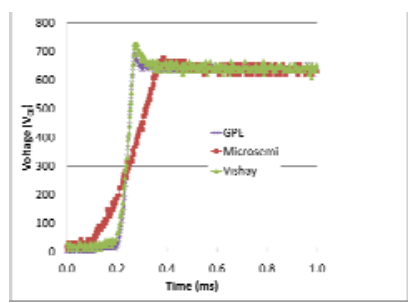

(b) $\mathrm{V}_{\mathrm{CE}}$ at Turn-off.

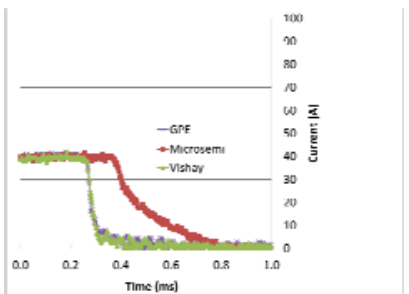

(d) $\mathrm{I}_{\mathrm{C}}$ at Turn-off.
Fig. 5. Transient switching waveforms at $600 \mathrm{~V}$ and $40 \mathrm{~A}$.

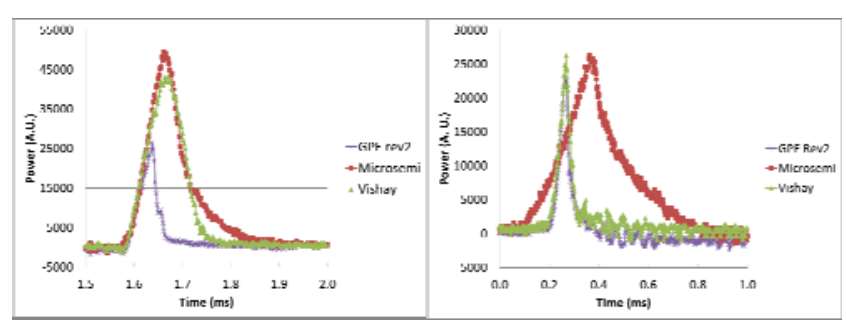

(a) Turn-on power loss.

(b) Turn-off power loss.

Fig. 6. Waveforms of switching power losses at junction temperature $150{ }^{\circ} \mathrm{C}$. 


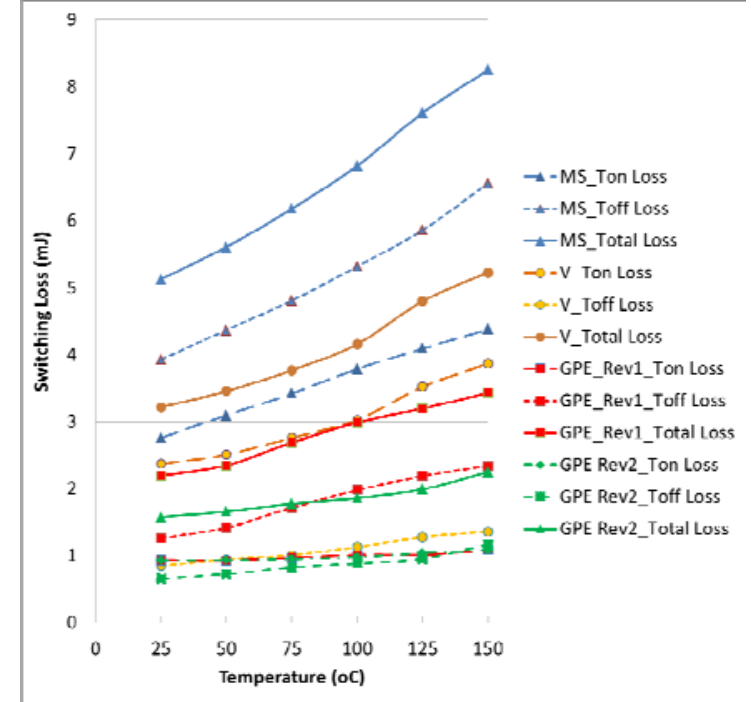

Fig. 7. Switching loss comparison at $600 \mathrm{~V}$ at $\mathrm{T}_{\mathrm{j}}=25^{0} \mathrm{C} \sim 150{ }^{\circ} \mathrm{C}$ and $\mathrm{I}_{\mathrm{C}}=40 \mathrm{~A}$.

Fig. 7 shows the turn-on switching loss $\left(\mathrm{T}_{\text {on }}\right)$ and the turn-off switching loss $\left(\mathrm{T}_{\text {off }}\right)$ as a function of junction temperatures at $\mathrm{V}_{\mathrm{CE}}=600 \mathrm{~V}$ and $\mathrm{I}_{\mathrm{D}}=40 \mathrm{~A}$. From the DPT test results of GPE's generation 2 hybrid module, the measured IGBT turn-on loss $\left(\mathrm{T}_{\text {on }}\right)$ is $0.93 \mathrm{~mJ}$ at $25{ }^{0} \mathrm{C}$ and $1.08 \mathrm{~mJ}$ at $150{ }^{\circ} \mathrm{C}$. The turn-off loss $\left(\mathrm{T}_{\text {off }}\right)$ is $0.65 \mathrm{~mJ}$ and 1.17 $\mathrm{mJ}$ at $25{ }^{\circ} \mathrm{C}$ and $150{ }^{\circ} \mathrm{C}$, respectively. In Vishay's Si booster module, the turn-off losses shows very similar results to GPE's module; however, the turn-on losses are more than double.

Since the discharge current of the SiC SBD's reverse recovery charge is independent of junction temperature, the increase to the turn-on loss of GPE's hybrid power module at a junction temperature $150{ }^{\circ} \mathrm{C}$ is only $16 \%$ when compared to the measured data at a junction temperature of $25{ }^{\circ} \mathrm{C}$. On the other hand, the turn-on loss of the Si boost diode based power modules (Microsemi: MS and Vishay: V) at a junction temperature of $150{ }^{0} \mathrm{C}$ is increased about $60 \%$ when compared to the value of the turn-on loss at a junction temperature of $25{ }^{0} \mathrm{C}$.

The total power losses are analyzed including diode conduction loss $\left(\mathrm{L}_{\mathrm{BD}}\right)$, IGBT conduction loss $\left(\mathrm{L}_{\mathrm{COND}}\right)$, turn-on switching loss $\left(\mathrm{L}_{\mathrm{ON}}\right)$, and turn-off switching loss $\left(\mathrm{L}_{\mathrm{OFF}}\right)$ at different switching frequency of $\mathrm{F}_{\mathrm{SW}}=25 \mathrm{kHz}, 50 \mathrm{kHz}$, and $100 \mathrm{kHz}$ with the fixed $\mathrm{V}_{\mathrm{CE}}=600 \mathrm{~V}, \mathrm{~T}_{\mathrm{j}}=150{ }^{\circ} \mathrm{C}$, and $\mathrm{I}_{\mathrm{C}}=10 \sim 40$ A as shown in Fig. 8.

In GPE's rev. 2 hybrid power module, by optimizing the doping concentration of the field stop trenched IGBT, the conduction losses and switching losses are compromised. The normalized total power losses of the hybrid booster power module are shown in Fig. 9. When the power modules were operated at the same switching frequency, the GPE's Gen 2 hybrid booster module could reduce the power losses to $50 \%$ $\sim 400 \%$ depend on the switching frequencies when compared to the commercial Si based booster power modules.

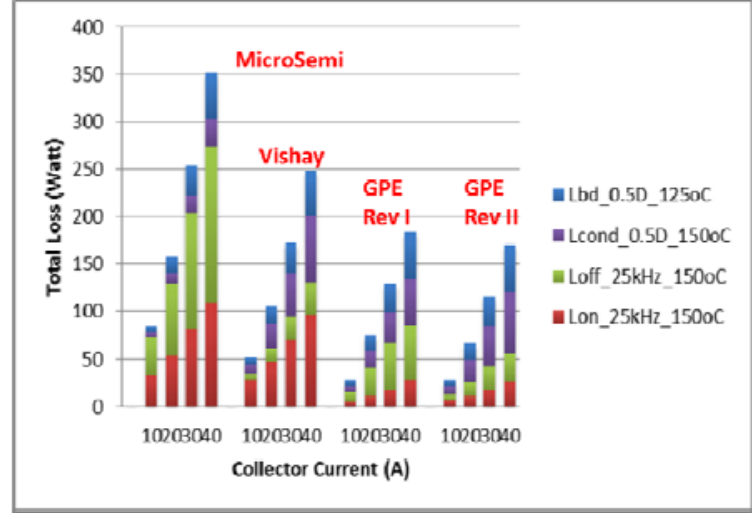

(a) $\mathrm{F}_{\mathrm{SW}}=25 \mathrm{kHz}$.

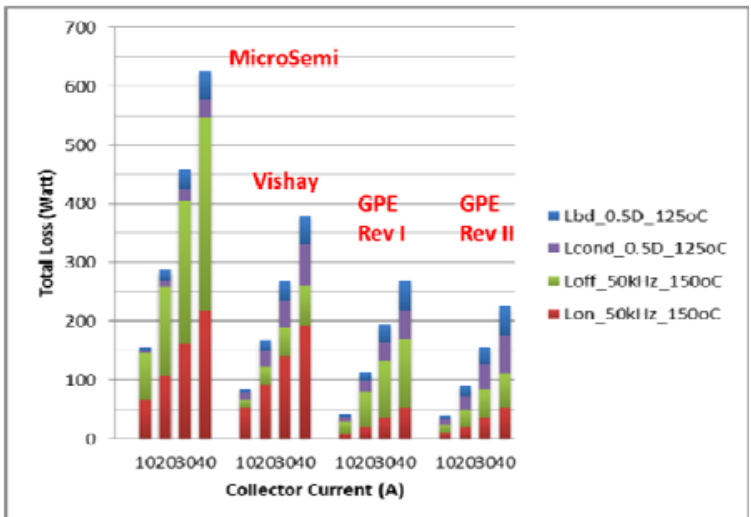

(b) $\mathrm{F}_{\mathrm{SW}}=50 \mathrm{kHz}$.

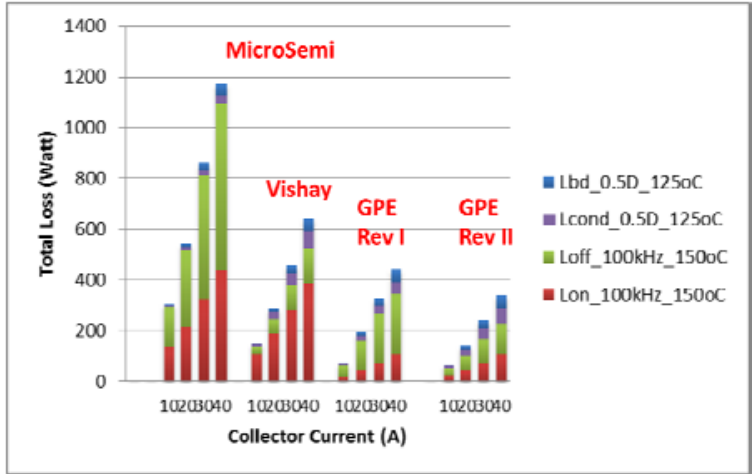

(c) $\mathrm{F}_{\mathrm{SW}}=100 \mathrm{kHz}$.

Fig. 8. Total power loss comparison within the boost modules at $\mathrm{I}_{\mathrm{C}}=10 \sim 40 \mathrm{~A}$ and $\mathrm{V}_{\mathrm{CE}}=600 \mathrm{~V}$.

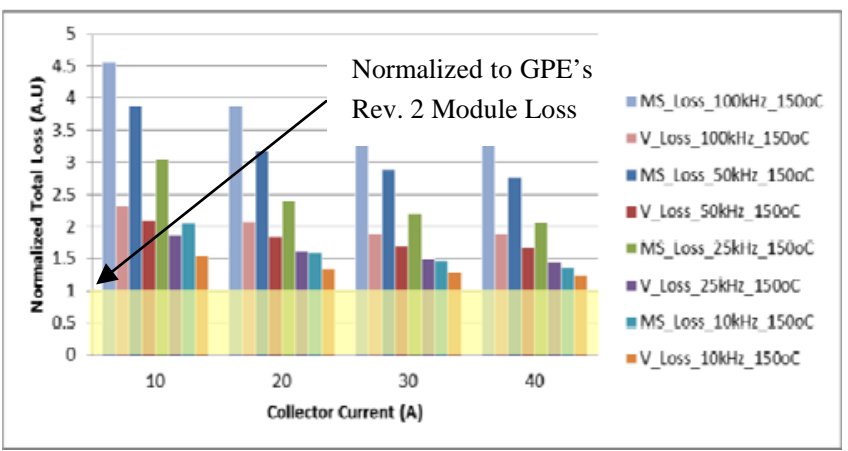

Fig. 9. Normalized total losses referenced to GPE Rev. 2 module for different switching frequency. 


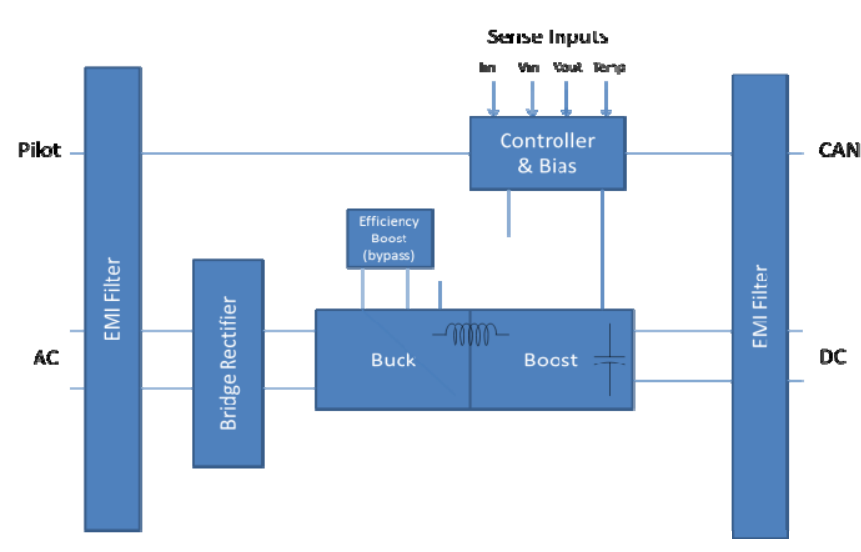

Fig. 10. The Functional block diagram of on-vehicle charger.

TABLE III

ON-VEHICLE CHARGER SPECIFICATIONS

\begin{tabular}{|l|c|c|c|}
\hline \multicolumn{1}{|c|}{ Parameters } & Symbol & Specifications & Units \\
\hline Rated Power & $\mathrm{P}_{\mathrm{OUT}}$ & 6.6 & $\mathrm{~kW}$ \\
\hline Input voltage range & $\mathrm{V}_{\mathrm{IN}}$ & $110 \sim 240$ & $\mathrm{~V}$ \\
\hline Output voltage & $\mathrm{V}_{\text {OUT }}$ & $200 \sim 500$ & $\mathrm{~V}$ \\
\hline Maximum input current & $\mathrm{I}_{\mathrm{IN} \_\mathrm{MAX}}$ & 30 & $\mathrm{~A}$ \\
\hline Switching frequency & $\mathrm{F}_{\mathrm{SW}}$ & 25 & $\mathrm{kHz}$ \\
\hline $\begin{array}{l}\text { Operating cooling } \\
\text { temperature (50 water: } \\
\text { 50 Ethylene glycol) }\end{array}$ & $\mathrm{T}_{\mathrm{C}}$ & $-20 \sim+65$ & ${ }^{0} \mathrm{C}$ \\
\hline
\end{tabular}

\section{III. $6.6 \mathrm{KW}$ ON-VEHICLE CHARGER}

In order to confirm the benefits of the Si IGBTs/ SiC SBDs hybrid booster power module, we developed and demonstrated the power conversion efficiency of the $6.6 \mathrm{~kW}$ non-isolated on-vehicle charger as a test platform. The functional block diagram of the on-vehicle charger is shown in Fig. 10. It is a Buck/Boost non-isolated topology that utilizes a single Buck/Boost Inductor. During normal operation where the battery voltage exceeds the peak of the AC input voltage, the charger operates in Boost mode and the Buck stage is turned on full. The Buck mode is only used when the peak of the AC input voltage is greater than the battery voltage and the Boost stage is turned off.

The on-vehicle charger specifications are shown in Table 3. The charger is designed with $6.6 \mathrm{~kW}$ rated power to meet the level 1 \& 2 charging requirement of PHEVs. The power factor, output voltage, and output current are controlled by the TMS320F28035 micro-controller from Texas Instrument.

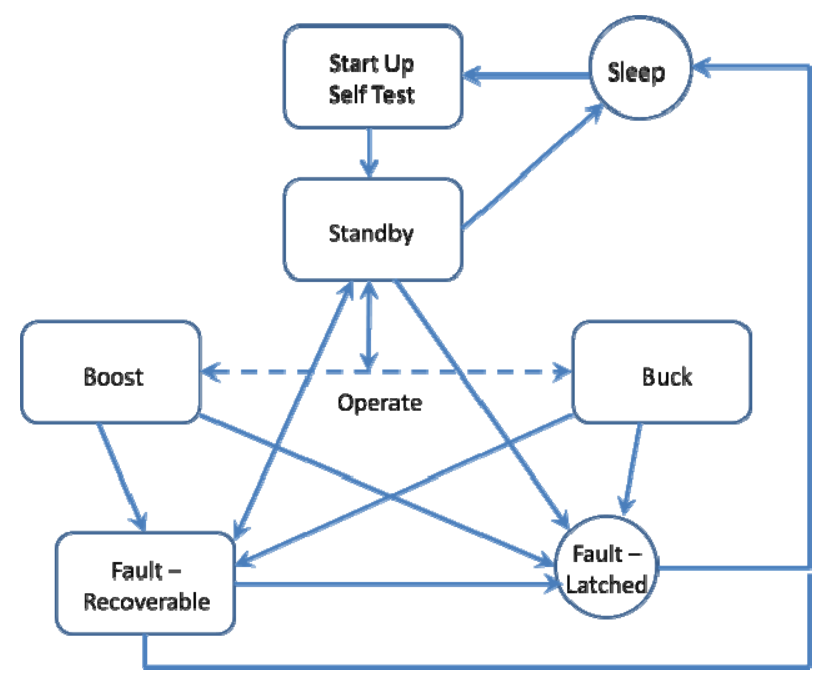

Fig. 11. State transition diagram of buck/boost mode control.

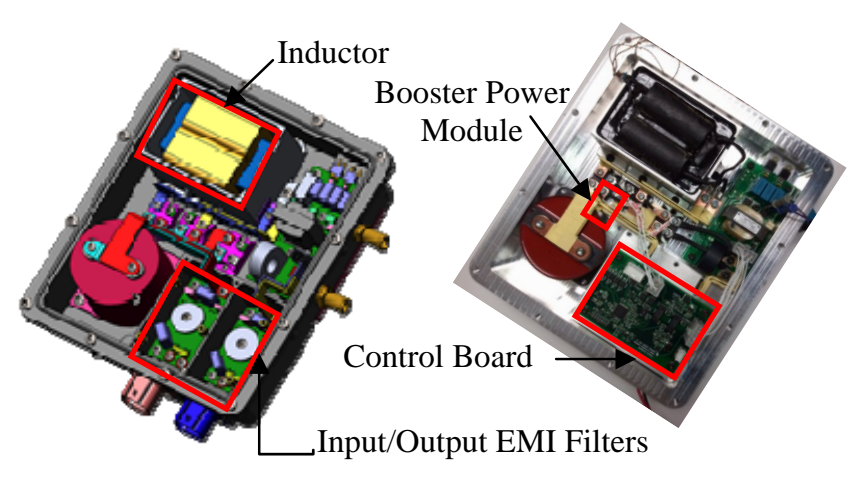

$\begin{array}{ll}\text { (a) SolidWorks model. } & \text { (b) Assembled charger. }\end{array}$

Fig. 12. Picture of the $6.6 \mathrm{~kW}$ on-vehicle charger.

Fig. 11 shows the state transition diagram of Buck/Boost control. Boost/Buck sub-modes are internally determined based on input/output voltage. Note that the charger only operates in Boost or in Buck Mode, and never switches both the Buck and Boost IGBTs at the same time. The charger operates most of the time in Boost Mode at nominal conditions, thus the power conversion efficiency in Buck Mode is not considered herein. For the performance comparison, a commercially available Silicon based boost module (both IGBT and PIN Boost Diode are Silicon) are used. The boost module used in the experiment is made by MicroSemi (MS) with the part number APT75GT120JU2 [14].

The developed $6.6 \mathrm{~kW}$ on-vehicle charger is shown in Fig. 12. The volume and weight of the charger is $\sim 5.4$ litter (230 x $260 \times 90 \mathrm{~mm}^{3}$ ) and $\sim 5.5 \mathrm{~kg}$, respectively. The hybrid Booster power module is replaced with Silicon based booster module for the performance comparison without change of any other system components or testing parameters. 


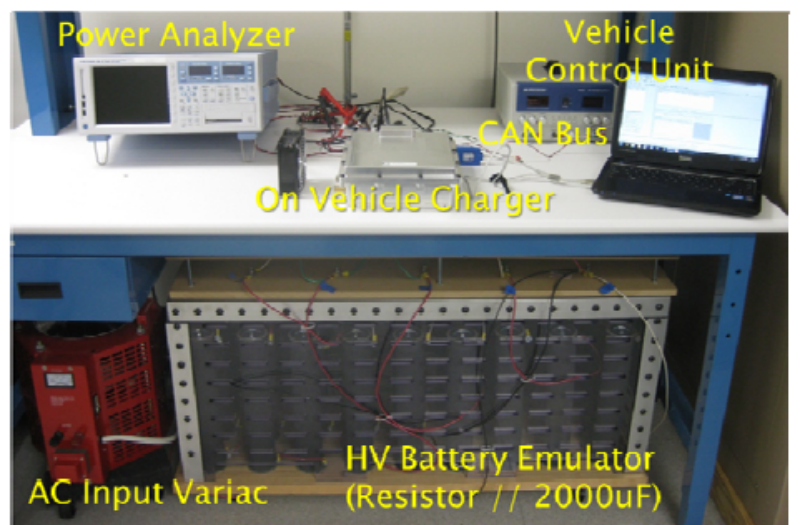

Fig. 13. Test setup for the 6.6kW on-vehicle charger.

\section{EXPERIMENTAL RESULTS}

Baseline data using the Si IGBT / Si Boost Diode Module is compared below with the same operating points and operating temperatures as the GPE Si IGBT / SiC SBD based hybrid booster module as described in section II.

Fig. 13 shows the test setup to measure the performances of the on-vehicle charger. The charging conditions are controlled by the vehicle control unit through a Car Area Network (CAN) bus. The resistor bank with paralleled 2000uF capacitor is used to emulate the battery. The power factor, power conversion efficiency, and total harmonic distortion data are measured with a Yokogawa Precision Power Analyzer (WT3000). The input AC voltage was adjusted from 110 Vac 240 Vac with a VARIAC.

While operating the on-vehicle charger with 125 Vac input voltage and constant $400 \mathrm{~V}_{\mathrm{DC}}$ output voltage, the measured power conversion efficiencies are shown in Fig. 14. The power conversion efficiency measured using Yokogawa WT3000 is improved about $2 \%$ across the operating powers and temperature ranges. As shown in Fig. 15, when the operation voltage was at $208 \mathrm{Vac}$ and the SiC SBD based hybrid Boost Module installed, the maximum power conversion efficiency of the on-vehicle charger was recorded $96.4 \%$. The hybrid boost module also showed much less sensitive at the elevated operating temperature when compared to the Si-based boost module.

Fig. 16 shows the input voltage, input current and the output voltage waveforms. The variation of $400 \mathrm{~V}_{\mathrm{DC}}$ output voltage is less than $3 \mathrm{Vp}-\mathrm{p}$ with $2000 \mathrm{uF} / / 62.5 \Omega$ load. The measured power factor is $0.98 \sim 0.993$ over the output power range as shown in Fig. 17. No significant difference in power factor is observed between MS and GPE modules The total harmonic distortion (THD) of the input AC current was not fully optimized. However, the THD value was stable and improved at higher output power as shown in Fig. 18.

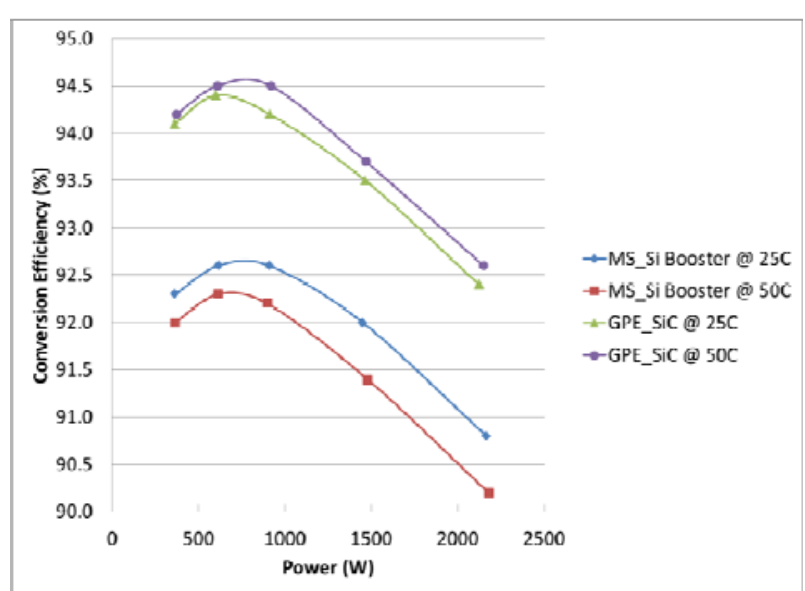

Fig. 14. Conversion Efficency Operating at 125 Vac Input and $400 \mathrm{~V}_{\mathrm{DC}}$ output voltage.

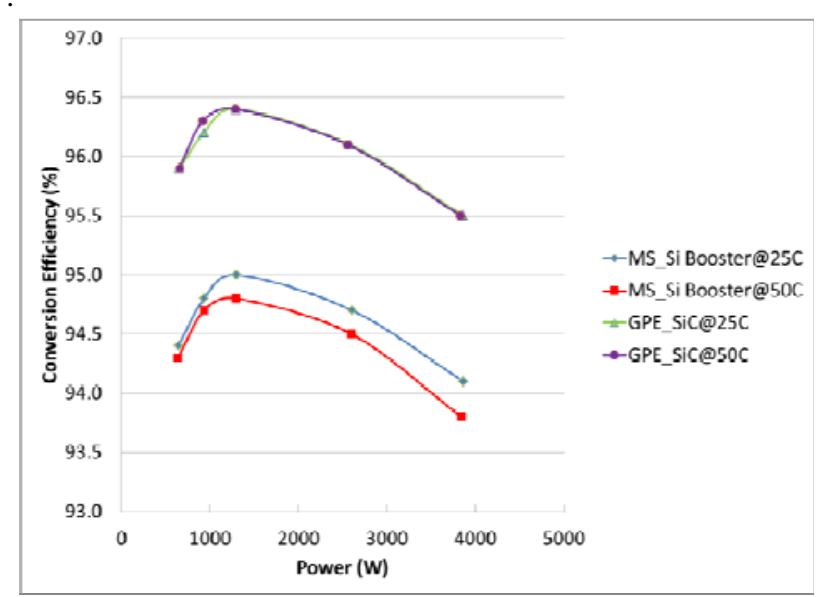

Fig. 15. Conversion Efficency Operating at 208 Vac Input and $400 \mathrm{~V}_{\mathrm{DC}}$ output voltage.

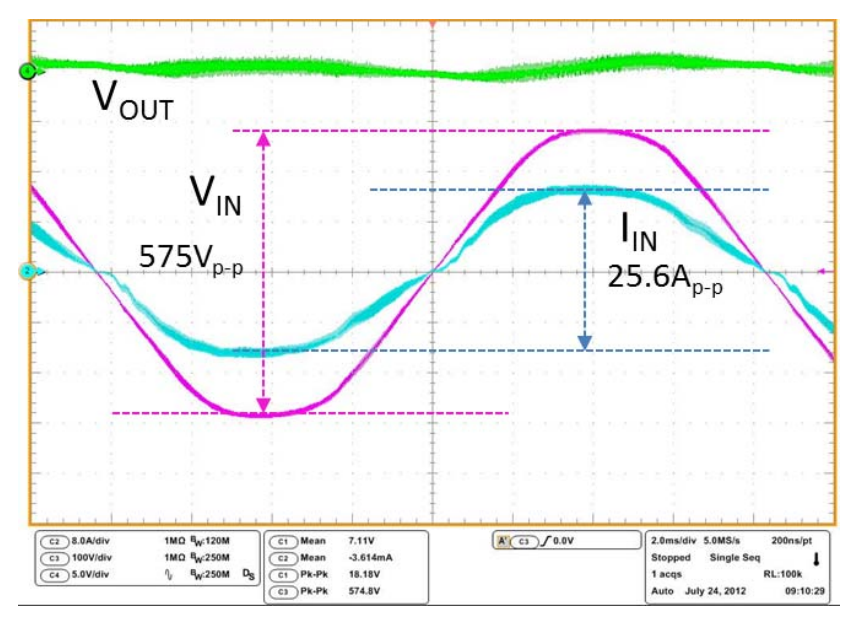

Fig. 16. Measured waveforms: input and output of the on board charger. Input Voltage (100 V/div) - purple, input current (8 $\mathrm{A} / \mathrm{div})$ - blue, and output voltage ripple (5 V/div) - green colored trace. 


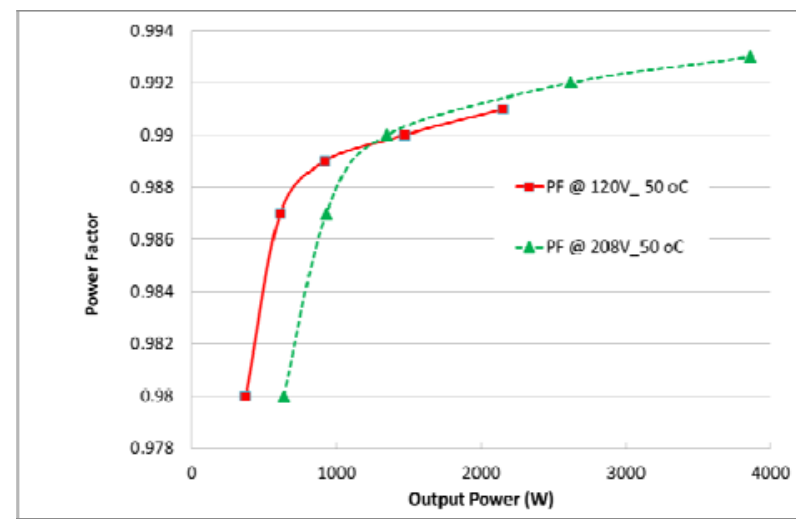

Fig. 17. Measured power factor at $400 \mathrm{~V}_{\text {DC }}$ Output voltage.

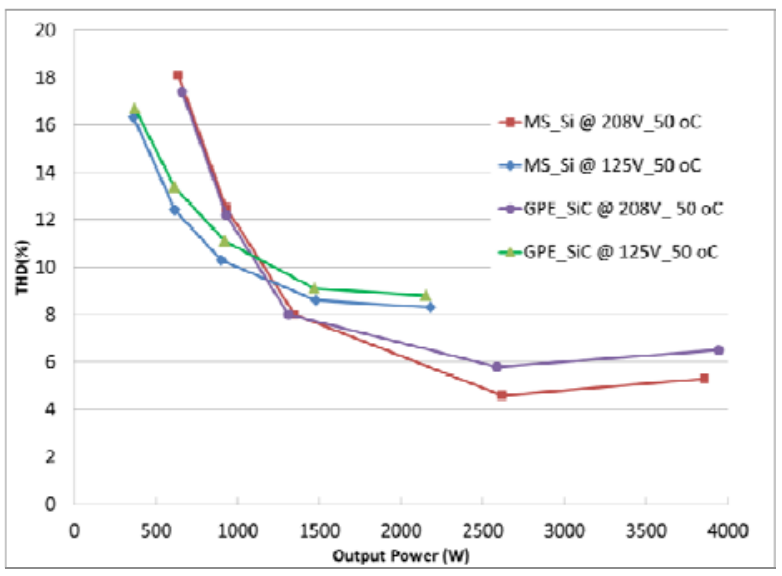

Fig. 18. Total harmonic distortion at $400 \mathrm{~V}_{\mathrm{DC}}$ output voltage.

\section{CONCLUSIONS}

We designed and developed a hybrid boost power module for on-vehicle charger applications. Based on analysis and evaluation results of the boost module, it is clear that replacing a Si PIN boost diode with a SiC SBD boost diode offers approximately $2 \%$ system efficiency improvement in the on-vehicle charger across the power and temperature operating range. This is considerable for a drop in replacement part in a practical design.

Utilizing SiC SBDs greatly reduced reverse recovery properties in power converters including on-vehicle chargers, DC/DC converters, and traction inverters will significantly improve overall power conversion efficiency of the HEVs/PHEVs/BEVs. For high temperature capability and robustness of power subsystems, SiC SBDs are certainly a natural choice for higher efficiency in fast switching applications. With the recent progress in the development of SiC switching devices like MOSFETs and IGBTs, the power converter will improve in efficiency, higher frequency switching, packaging size, and weight. Cost reduction of SiC devices will follow with increased utilization, economies of scale production, and improvements of device process with $150 \mathrm{~mm}$ SiC wafers.

\section{ACKNOWLEDGEMENT}

The authors appreciate Dr. Chris Yun and Dr. Harrison Oh of Trinno Technology for providing us the trenched field-stop Si IGBTs.

\section{REFERENCES}

[1] F. R. Kalhammer, H. Kamath, M. Duvall, M. Alexander, and B. Jungers, "Plug-in hybrid electrical vehicles: promise, issues, and prospects," Proceedings of EVS 24 International Battery, Hybrid and Fuel Cell Electric Vehicle Symposium, pp. 1-11, May 2009.

[2] D. P. Tuttle and K. M. Kockelman, "Electrified vehicle technology trends, infrastructure implications, and cost comparisons," Journal of the Transportation Research Forum, Vol. 51, No. 1 pp. 35-51, 2012.

[3] K. Morrow, D. Karner, and J. Francfort, "Plug-in hybrid electrical vehicle charging infrastructure review," US Department of Energy Vehicle Technologies Program- Advanced Vehicle Testing Activity Annual Report, INL/EXT-08-15058, November 2008.

[4] A. Emadi, Y. J. Lee, and K. Rajashekara, "Power electronics and motor drives in electric, hybrid electric, and plug-in hybrid electric vehicles," IEEE Trans. Ind. Electron., Vol. 55, No. 6, pp. 2237-2245, Jun. 2008.

[5] A. Elasser, and T. P. Chow, "Silicon carbide benefits and advantages for power electronics circuits and systems," Proceeding of IEEE, Vol. 90, No. 6, pp. 969-986, Jun. 2002.

[6] F. Musavi, W. Eberle, and W. G. Dunford, "A high performance single-phase bridgeless interleaved PFC converter for plug-in hybrid electric vehicle battery chargers," IEEE Trans. Ind. Appl., Vol. 47, No. 4, pp. 1833-1843, Jul. 2011.

[7] J. S. Kim, G. Y. Choe, H. M. Jung, B. K. Lee, Y. J. Cho, and K. B. Han, "Design and implementation of a high-efficiency on-board battery charger for electric vehicles with frequency control strategy," in Proc. IEEE Vehicle Power and Propulsion Conference (VPPC'10), pp. 1-6, Sep. 2010.

[8] Md. M. Alam, W. Eberle, and F. Musavi, "A zero voltage switching semi-bridgeless boost power factor corrected converter for plug-in hybrid electric vehicle battery chargers," in IEEE Applied Power Electronics Conference and Exposition (APEC), pp. 2625-2630, 2012.

[9] H. Tsai, T. H. Hsia, and D. Chen, "A family of zero voltage-transition bridgeless power-factor -correction circuits with a zero-current-switching auxiliary switch," IEEE Trans. Ind. Electron., Vol. 58, No. 5, pp. 1848-1855, May 2011.

[10] F. Xu, D. Jiang, J. Wang, F. Wang, L. M. Tolbert, T. J. Han, J. Nagashima, and S. J. Kim, "High temperature packaging of $50 \mathrm{kw}$ three-phase sic power module," Proceedings of the 8th International Conference on Power Electronics (ICPE) -ECCE Asia, pp. 2427-2433, May 2011.

[11] www.trinnotech.com, Trinno Technology IGBT datasheet of Part Number TGAN25N120ND, Jul. 1th 2012.

[12] D. Jiang, R. Burgos, F. Wang, and D. Boroyevic, "Temperature dependent characteristics of SiC devices: Performance evaluation and loss calculation," IEEE Trans. Power Electron., Vol. 27, No. 2, pp. 1013-1024, Feb. 2012.

[13] http://www.vishay.com, Vishay Si IGBT/ Si PIN booster power module datasheet of Part Number GB50LA120UX, Jul 22th 2010.

[14] www.microsemi.com, MicroSemi Si IGBT/ Si PIN booster power module datasheet of Part Number APT75GT120JU2, Nov. 3th 2009. 


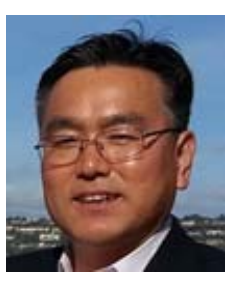

Timothy Junghee Han was born in Pusan, Korea. He obtained B.S. and M.S. degree in Electronics from Busan National University and Ph.D. degree in Electrical Engineering from KAIST in 1986, 1988, and 1998, respectively. He has over 20 years experiences in semiconductor devices, $\mathrm{SiC}$ power devices, optical components, module packaging, and power electronics systems. From 1988 to 1998, he was a Principal Engineer at ETRI, Taejon, Korea. From 1999 to 2001, he was a Principal Research Engineer with the Lucent Technologies, U.S.A. Since 2008, he is a Senior Manager and leads development of the advanced power electronics modules and subsystems using $\mathrm{SiC}$ power devices for the next generation hybrid electric vehicles (HEV) and alternative energy industry applications at Global Power Electronics, Inc. He has authored 23 technical journal papers, 12 patents, and made 16 presentations at prestigious international conferences.

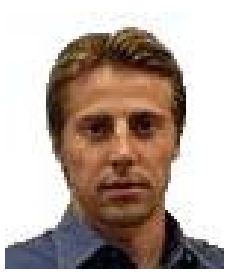

Jared Preston was born in Wisconsin, U.S.A. He received his B.S. in Electrical Engineering from University of California, Los Angeles (UCLA) in 2005. From 2006 to 2011 he was with ISE where he worked on the development of hybrid drive systems incorporating battery/Ultra Cap energy storage management. He is currently with Global Power Electronics developing high power, fast switching converters utilizing $\mathrm{SiC}$ semiconductors. His interests are in advanced power electronics subsystems created with wide bandgap devices in mind that will power the alternative energy industry to come.

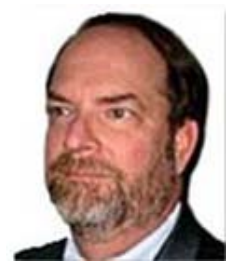

David Ouwerkerk was born in California, U.S.A. His B.S. Electrical Engineering is from Loyola Marymount University in 1974, Los Angeles and M.S. Electrical Engineering (specialty in Circuit Theory) is from University of California, Los Angeles (UCLA) in 1980. He has over 30 years' experience in military (ground, airborne, and space) systems and automotive (EVs, HEVs, and Hydrogen Fuel Cell) applications. From 2000 to 2011, he has designed, contributed to, and managed a number of power systems including: GM's EV1 and Volt charging systems at General Motors Advance technology Center. Since 2011, he is Director of Power Sub-Systems and Charging at Global Power Electronics, Inc. 